\title{
Experimental investigation of kinematic and thermal localizations of perforated plate under plastic deformations
}

\author{
by L. Li, C. Martel, A. El Bartali, J.-F. Witz and É. Charkaluk
}

Laboratoire de Mécanique de Lille, CNRS FR 3723, F-59655 Villeneuve d'Ascq, France, li.li@ec-lille.fr

\begin{abstract}
In order to investigate the heterogeneous phenomena induced by structural geometrical effect, a perforated plate with a circular hole in the centre is experimentally analysed under monotonic loading. With the optical face-to-face full-field measurement techniques, the heterogeneous thermomechanical behaviour of this specimen model is investigated in both elastic and inelastic deformation stages. This work allows to provide the supplementary elements for the identification of elastoplastic constitutive models by using coupled thermomechanical heterogeneous full-fields.
\end{abstract}

1.

\section{Introduction}

It has been recognized that, understanding the material behaviour and prediction of initial cracks starting at notch tips because of strain concentrations are of great interest to engineers and scientists. Using the combined imaging techniques allows to access to the evolution of the mechanical and thermal fields through the specimen's deformation. Naturally, the kinematic field concentration and thermal field concentration at both hole side could be respectively highlighted by Digital Image Correlation (DIC) and Infrared Thermography (IRT).

2.

\section{Experimentation}

The as-received material used in this study consists in a 2,5mm thick low alloy steel plate (35NCD16). The central hole has a diameter of $0,6 \mathrm{~mm}$ in a rectangular zone of interest (ZOI) with width of $10 \mathrm{~mm}$ and height of $50 \mathrm{~mm}$ in gauge length.

As mentioned previously, the tested specimen is observed on on side with a visible camera, and the opposite side is recorded simultaneously by an IR camera, as shown in figure 1.

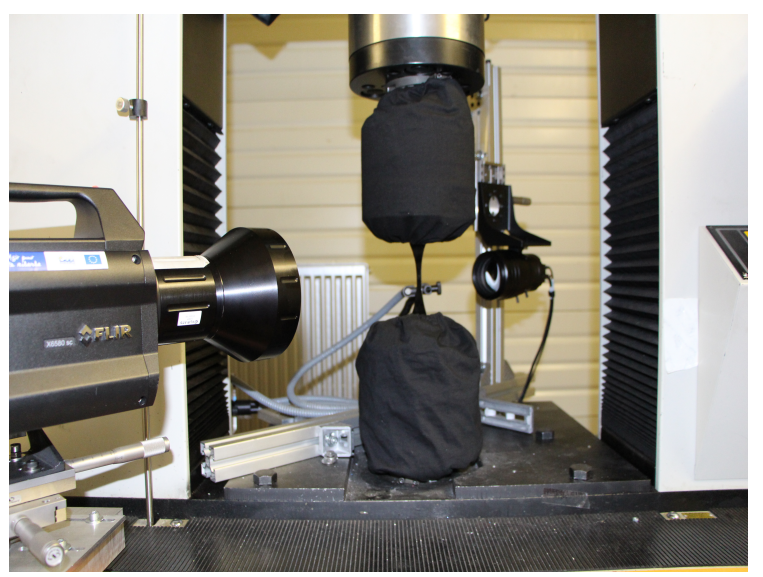

Fig. 1. Experimental setup

The main characteristics of the cameras are reported in Table 1. As the kinematic and thermal data come from different acquisition systems, the spatial and temporal matchings will be performed to combine all experimental data for investigation.

Table 1: Main camera characteristics

\begin{tabular}{|c|c|c|}
\hline & Image size (pixel) & Frame rate $(\mathrm{Hz})$ \\
\hline IR: FLIR X6580 sc & $512 \times 640$ & 80 \\
\hline Visible: XIMEA MQ042MG-CM & $2048 \times 2048$ & 80 \\
\hline
\end{tabular}




\subsection{1/qirt.2016.073}

3.

\section{Discussions}

In the literature, the perforated plates, having different hole diameters in the centre, have been both experimental used in [1] and numerically investigated in [2] for analyse and identification, which were only focused in kinematic aspect.

Using the heat generation induced by mechanical loading, the thermal evolutions of specimen, which are respectively associated with the thermoelastic coupling and the plastic dissipation, can be thermodynamically investigated. If one considers linear thermoelasticity, this thermal linearity may be retrained until the first occurrence of dissipative plastic phenomena [3].

With fully-coupled thermomechanical measurements, the objective of this study is firstly to investigate experimentally the kinematic and thermal localizations during the deformation, and then to contribute to a better knowledge of the thermomechanical consistency on elastoplastic model identification, in particular for its hardening behaviour [4].

\section{REFERENCES}

[1] Molimard J., Le Riche R., Vautrin A., Lee J., "Identification of the four orthotropic plate stiffnesses using a single open-hole tensile test ". Experimental Mechanics, vol. 45, pp. 404-411, 2005.

[2] Watanabe O., Bubphachot B., Matsuda A, Akiyama T., "Stress and Strain Locus of Perforated Plate in Inelastic Deformation--Strain-Controlled Loading Case ". Journal of Pressure Vessel Technology, ASME, vol. 134, pp. 031207-1-13, 2012.

[3] Charkaluk E., Seghir R., Bodelot L., Witz J-F., Dufrénoy P., "Microplasticity in Polycrystals: A Thermomechanical Experimental Perspective". Experimental Mechanics, vol. 55, pp. 741-752, 2015.

[4] Avril S., Bonnet M., Bretelle A.-S., Grédiac M., Hild F., lenny P., Latourte F., Lemosse D., Pagano S., Pagnacco E., Pierron F., "Overview of Identification Methods of Mechanical Parameters Based on Full-field Measurements ". Experimental Mechanics, vol. 48, pp. 381-402, 2008. 